\title{
SYNTHESIS AND CHARACTERIZATION OF DYE-DOPED POLYMER FILMS FOR NON-LINEAR OPTICAL APPLICATIONS
}

\author{
Dmytro Mishurov ${ }^{1}, 2, \otimes$, Andrii Voronkin', Alexander Roshal ${ }^{2}$, \\ Sergiy Bogatyrenko ${ }^{3}$, Olga Vashchenko ${ }^{4}$
}

https://doi.org/10.23939/chcht13.04.459

\begin{abstract}
In this work polymer nonlinear optical (NLO) materials in the form of thin films based on 3,7,3,4tetrahydroxyflavone and diglycidyl ether of bisphenol A were obtained and investigated. It was found that the influence of the chromophore concentration on values of the macroscopic NLO susceptibilities $\left(\chi^{(2)}\right.$ of doped polymer films has extreme character. The maximum value of $\chi^{(2)}$ is $6.11 \mathrm{pm} / \mathrm{V}$ at the concentration of dopant $20 \mathrm{wt} \%$.
\end{abstract}

Keywords: polymer composite, doped epoxy polymer, chromophore, nonlinear optical susceptibility, 3,7,3',4'tetrahydroxyflavone.

\section{Introduction}

The fast development of photonics and optoelectronics would be impossible without polymer composite materials with nonlinear optical (NLO) properties along with using traditional inorganic crystals. The main problem with the use of inorganic crystals is associated with the difficulty of growing samples of large sizes and shapes. NLO polymer materials compared to inorganic crystals, without aforementioned shortcomings, have a faster NLO response, and they have higher technological and economical indices [1-3]. It should be noted that the NLO response of the chromophores doped polymer NLO materials directly depends on the NLO response of the chromophore compound, which is a dopant in the polymer matrix. Consequently,

\footnotetext{
${ }^{1}$ National Technical University "Kharkiv Polytechnic Institute",

2, Kyrpychov St., 61002 Kharkiv, Ukraine

${ }^{2}$ Institute of Chemistry at V.N. Karazin Kharkiv National University

4, Svoboda Sq., 61022 Kharkiv, Ukraine

${ }^{3}$ School of Physics at V.N. Karazin Kharkiv National University 6, Svoboda Sq., 61022 Kharkiv, Ukraine

${ }^{4}$ Institute for Scintillation Materials of STC "Institute for Single

Crystals" of NAS of Ukraine,

60, Nauky Ave., 61072 Kharkiv, Ukraine

mishurov@kpi.kharkov.ua

(C) Mishurov D., Voronkin A., Roshal A., Bogatyrenko S., Vashchenko O., 2019
}

chromophores are the source of macroscopic NLO activity of doped polymers formed by the "guest-host" type [4, 5].

In view of all the above, the NLO properties of such polymeric materials can be varied and optimized, for example, by varying the chromophore concentration.

That is why, the search for effective organic chromophores with high values of the dipole moment $(\mu)$, and hence the quadratic polarizability at the molecular level $(\beta)$ is currently underway [6]. In this paper, polymer films doped with 3,7,3',4'-tetrahydroxyflavone (fisetin) were investigated. It is a natural pigment. Chemical structure of fisetin is shown in Fig. 1. According to its geometric and electronic structure, fisetin belongs to the group of flavonols [7].

Previously [8] it was shown that the electronic transitions of the flavonoids are localized in orthobenzaldehyde ( $\mathrm{C}$ ring), chromone $(\mathrm{A}+\mathrm{C}$ rings) and phenyl (B ring) fragments of the molecule. Such chemical structure of fisetin promotes its noncentrosymmetric structure (i.e. the absence of a symmetry center) and therefore makes this compound promising for the creation of NLO polymer materials on its basis.

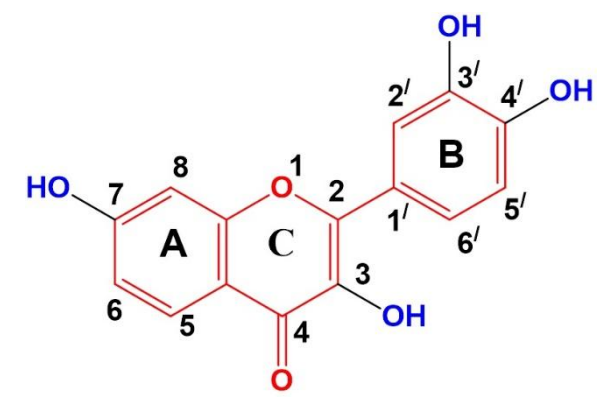

Fig. 1. Chemical structure of 3,7,3, ,' -tetrahydroxyflavone

It should be noted that incorporation of different dopants into the polymer matrices has certain limitations, which are caused by aggregation of chromophore molecules. The aggregation of the chromophore molecules, which have high values of permanent dipole moment in a ground state, leads to the origin of dipole- 
dipole interaction between them, due to which they are oriented in the polymer matrix in antiparallels. This fact prevents their optimal packing and decreases macroscopic NLO properties of the polymer system $[9,10]$. There is a certain concentration limitation of dopant incorporation into a polymer matrix.

Thus, the purpose of this work is to investigate the influence of optical, thermal and morphological properties on the nonlinear optical activity of polymer films based on epoxy polymer, doped with 3,7,3',4'-tetrahydroxyflavone and to determine optimal concentration of dopant, under which the NLO properties of polymer materials would not become worse.

\section{Experimental}

\subsection{Materials}

Diglycidyl ether of Bisphenol A (DGEBA, Epoxy 520, EEW 184 g/eq., Spolchemie) and 3,7,3,4tetrahydroxyflavone (fisetin) were used for the current investigations. Diethylenetriamine (DETA, Dow Epoxy) was used as a hardener. Previously cleaned and dried acetone was used as the solvent.

\subsection{Doped Polymer Films Preparation}

Polymer films were prepared on glass substrates via spin-coating technique with a chromophore concentrations of $5,10,20,30,40$, and $50 \mathrm{wt} \%$ relative to DGEBA. Necessary amount of fisetin/ DGEBA mixture was dissolved in acetone at the concentration of $0.1 \mathrm{~g} / \mathrm{ml}$. Then DETA was added to the resulting solution with DETA/DGEBA stoichiometric ratio of 1:10\% (w/w). The prepared solutions were spin-coated at $1000 \mathrm{rpm}$ for $30 \mathrm{~s}$ onto pre-cleaned glass cover slides of $170 \mu \mathrm{m}$ thickness. To remove the residual solvent, the polymer films were dried at $323 \mathrm{~K}$ under vacuum for $8 \mathrm{~h}$ and then additionally heated at $373 \mathrm{~K}$ for $3 \mathrm{~h}$.

\subsection{Doped Polymer Films Poling}

Poling of the polymer films on glass substrates was carried out in a corona discharge field at $403 \mathrm{~K}$ for 40 min. During poling procedure, the electric current was $2.5 \mu \mathrm{A}$ at the electric voltage of $7 \mathrm{kV}$ on a corona electrode. After poling the polymer films were cooled to room temperature and the electric current was turned off.

\subsection{Characterization}

UV-Visible spectra of the polymer films were recorded using UV-VIS Spectrophotometer Hitachi-U3210 in the range of 700-300 $\mathrm{nm}$. Mathematical processing of the spectra was performed using the Spectra Data Lab software package [11]. FTIR spectra were obtained using
Spectrum One spectrophotometer (Perkin Elmer) in $\mathrm{KBr}$ in the range of $4000-400 \mathrm{~cm}^{-1}$. Photomicrographs of the polymer films surfaces were obtained using scanning electronic microscopy (JSM JEOL Model 840) with operating voltage of $20 \mathrm{kV}$. Since the polymer films under investigation are dielectrics, the preliminary vacuum deposition of electrically conducting chrome layer of $100 \mathrm{~nm}$ thickness on the films surfaces was made.

DSC thermograms of the polymer films were obtained using Mettler DSC 1 microcalorimeter, in the temperature range of $273-453 \mathrm{~K}$ and at the heating rate of $10 \mathrm{~K} / \mathrm{min}$. The weight of the sample was $6-9 \mathrm{mg}$. The glass transition temperature $\left(T_{g}\right)$ of polymer composites was determined by the position of the maximum of the DSC curves first derivative.

The thickness of the polymer films was measured using Linnik-type interference microscope MII-4, which was $1 \mu \mathrm{m}$. The Linnik interferometer configuration (a kind of the Michelson configuration) was described previously [12].

\section{Results and Discussion}

\subsection{Optical Properties of Doped Polymer Films}

FTIR spectra of the fisetin doped polymer films are presented in Fig. 2. It can be seen that FTIR spectra of all samples have a broad absorption band in the region of $3178-3500 \mathrm{~cm}^{-1}$, which corresponds to the stretching vibrations of phenolic OH-groups of fisetin and $\mathrm{OH}-$ groups of the epoxy polymer. In the region of 2920 and $2850 \mathrm{~cm}^{-1}$, C-H symmetric and asymmetric stretching vibrations of methyl $(\mathrm{CH})$ and methylene $\left(\mathrm{CH}_{2}\right)$ groups, respectively, are observed. Absorption bands in the optical range of $1580-1621$ and $1450-1510 \mathrm{~cm}^{-1}$ characterize the stretching vibrations of $\mathrm{C}=\mathrm{C}-\mathrm{C}$ group [13]. The absorption band near $568 \mathrm{~cm}^{-1}$ can be attributed to deformation vibrations of the aromatic cycle.

It should be noted that the band assigned to deformation vibrations of oxyrane cycle at $910-920 \mathrm{~cm}^{-1}$ was not detected in any FTIR spectra. This indicates the absence of free epoxy groups and proves the completion of DGEBA crosslinking reaction. In addition, we did not find a band around $1700-1720 \mathrm{~cm}^{-1}$ assigned to acetone carbonyl group. This fact confirms the absence of residual solvent - acetone [14].

Fig. 3 shows UV-Visible absorption spectra of the films containing different concentrations of the dopant in the optical range from 700 to $300 \mathrm{~nm}$. As can be seen from Fig. 3 , with increasing concentration of dopant there is an increase in absorption intensity. The reason is the increase in the number of dopant molecules, which in turn leads to the increase of chromophore molecules self-absorption. 


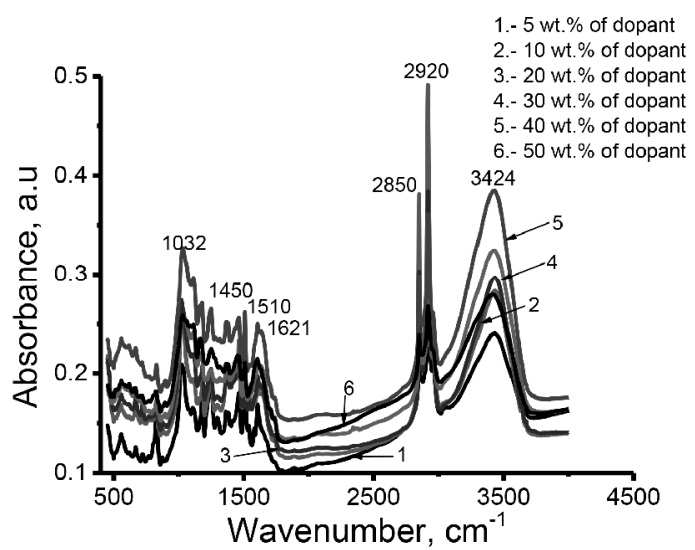

Fig. 2. FTIR spectra of doped polymer films

The spectra given in Fig. 3 are a superposition of simpler spectral curves. Deconvolution of the obtained spectral curves (Fig. 4) shows that there are at least two curves which may be assigned to different forms of dopant: neutral and anionic forms. In our opinion, this phenomenon may be explained by the fact that at DGEBA polymerization in situ, DETA ( $\mathrm{pH} 12.5$ ) was used as a curing agent. Under such conditions a lot of dopant molecules are in anionic form. With the increase in the dopant concentration from 5 to $50 \mathrm{wt} \%$ in the polymer system, the number of molecules in a neutral form becomes less than that in anionic form. Quantitative redistribution between these two forms with increasing concentration of dopant in the polymer matrix leads to different positions of the resulting maxima on the spectral curves (Fig. 4).

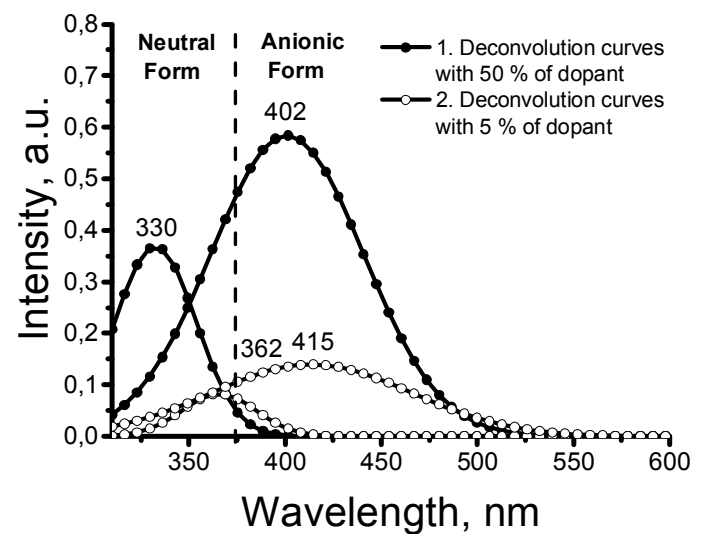

Fig. 4. The deconvolution curves of doped polymer films absorption spectra

Moreover, Fig. 3 shows that the doped polymer films exhibit optical transparency of about $96 \%$ in the region of 700-600 nm. Optical losses in this optical range were from 0.2 to $0.05 \mathrm{~dB} / \mathrm{cm}$ depending on the dopant concentration. Below this region $(600-300 \mathrm{~nm})$ there is a

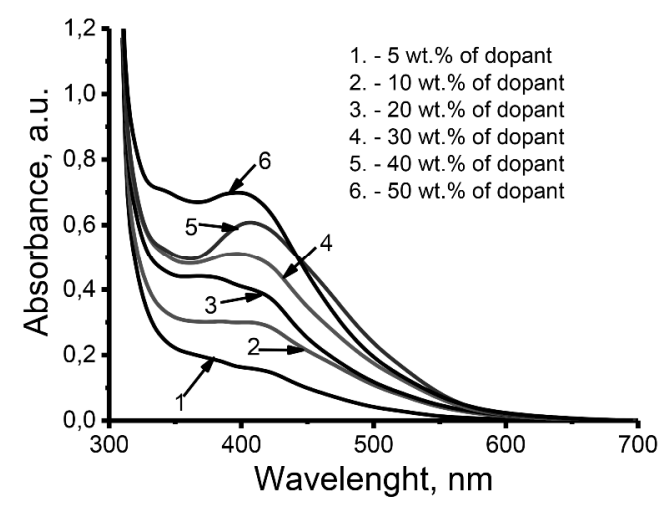

Fig. 3. Absorption spectra of doped polymer films

decrease in the optical transparency of the obtained doped polymer films, occured due to the self-absorption of dye molecules.

\subsection{Thermal Properties of Doped Polymer Films}

Determination of the thermal properties of polymer NLO systems is very important: i) properties determine the interval of systems operation in the laser radiation conditions; ii) they allow to make predictions about the morphology of such systems, as well as the conditions for their poling, since it is well-known that the poling of polymer materials must occur at temperatures higher than the glass transition temperature [15].

The dependence of the glass transition temperature $\left(T_{g}\right)$ of doped polymer films on dopant concentrations is shown in Fig. 5. The increase of fisetin concentration from 5 to $10 \mathrm{wt} \%$ causes a sharp increase of $T_{g}$ (from 316.6 to $330.6 \mathrm{~K}$ ). With further increase of the dye concentration (from 20 to $50 \mathrm{wt} \%$ ) the $T_{g}$ value of doped polymer films varies slightly from 330.6 to $333.7 \mathrm{~K}$.

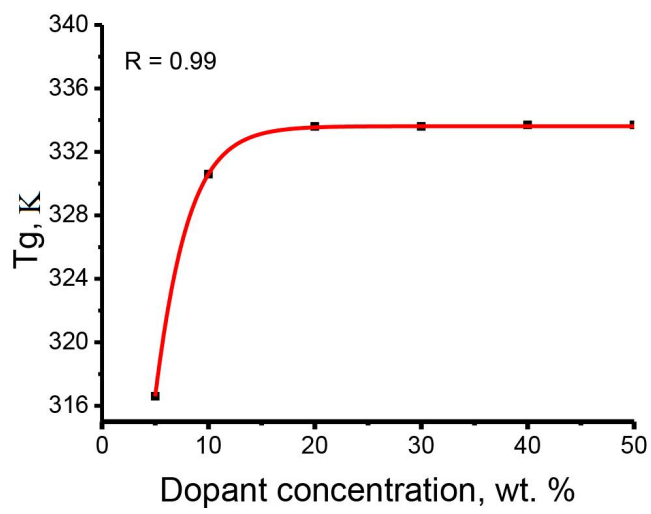

Fig. 5. The dependence of the glass transiti on temperature of the filled polymer films on the dopant concentration 
In our opinion, thermal properties of doped amorphous polymer systems can be satisfactorily described by percolation theory. According to this theory, at slow change in the dopant concentration, the thermal properties of amorphous doped system should be changed abruptly near the critical point or percolation threshold $[16,17]$. Thereby, thermal behaviors of investigated doped polymer films demonstrated that there is the percolation threshold near the dopant concentration of 15 $20 \mathrm{wt} \%$.

\subsection{Morphology of Doped Polymer Composites}

The microphotographs shown in Fig. 6 reflect the morphology of polymer films based on epoxy polymerfisetin composites. As one can see from Figs. $6 \mathrm{a}$ and $6 \mathrm{~b}$, at the fisetin concentration of $20 \mathrm{wt} \%$ a separate dye phase with a clearly defined distribution border is formed. The increase of the dopant concentration from 20 to $30 \mathrm{wt} \%$ leads to the fact that isolated inclusions of dye are merging with polymer phase and are forming the structure that contains two extended interpenetrating phases, both doped polymers and undoped polymers (Fig. 6d). In this case, it is impossible to distinguish which polymer phase is a matrix.

Thus, we can conclude that the transition region from one type of phase structure to another type is near the percolation threshold, which determines the region of the phases inversion. It should be noted that the morphological investigations have confirmed previous results, which were made on the basis of optical and thermal investigations.

\subsection{Influence of Chromophore Concentration on Nonlinear-Optical Properties of Doped Polymer Films}

To determine the influence of the chromophore concentration on NLO activity of doped polymer films, for each concentration of dopant the values of macroscopic second-order NLO susceptibility $\left(\chi^{(2)}\right)$ were calculated. The calculation was made according to Eq. (1) [18]:

$$
\chi^{(2)}(-2 \omega, \omega, \omega)=N \beta(-2 \omega, \omega, \omega) F\left\langle\cos ^{3} \theta\right\rangle
$$

where $N$ is molecular number density of chromophore; $\beta$ is molecular first hyperpolarizability of chromophore; $F$ is the local field correction factor; $\cos ^{3} \theta$ is the average factor of alignment of chromophore molecules along the applied electric field:

$$
\left\langle\cos ^{3} \theta\right\rangle=(0.6 \Phi)^{1 / 2}
$$

where $\Phi$ is the order parameter characterizing the polinginduced dipole re-orientation of the chromophore moieties.

The order parameter $\Phi$ was calculated using absorption values of the films after $\left(A_{1}\right)$ and before $\left(A_{0}\right)$ poling according to Eq. (3) [19]:

$$
\Phi=1-\frac{A_{1}}{A_{0}}
$$

The results of calculations are given in Table.

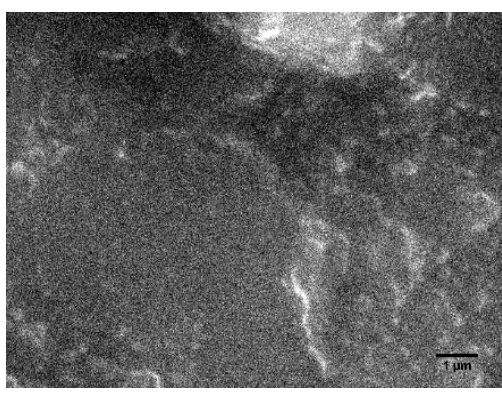

a)

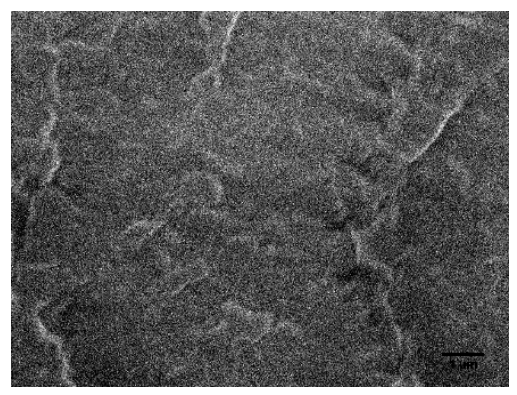

d)

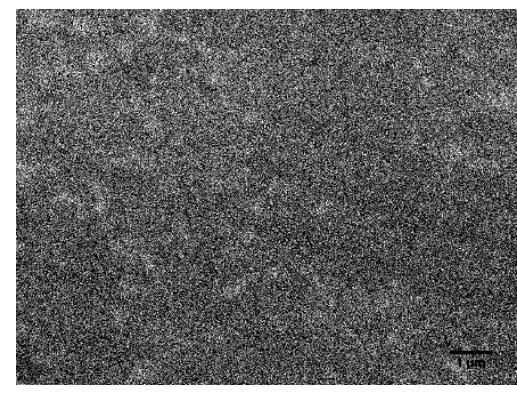

b)

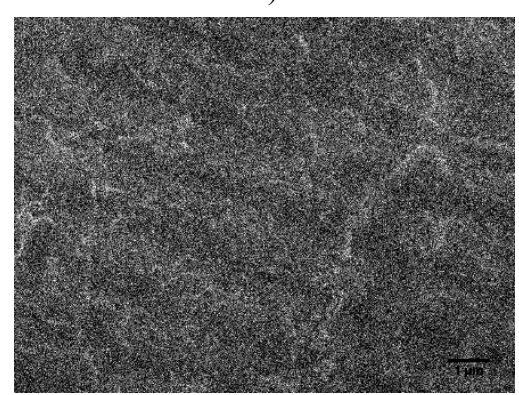

e)

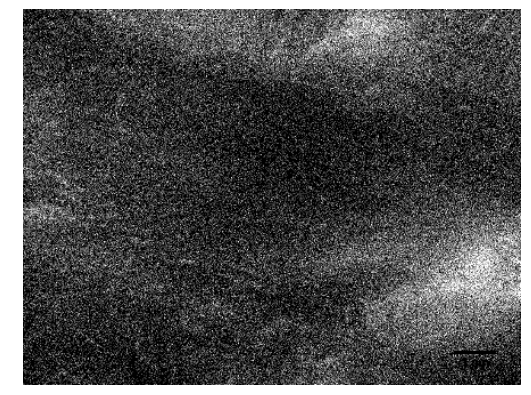

c)

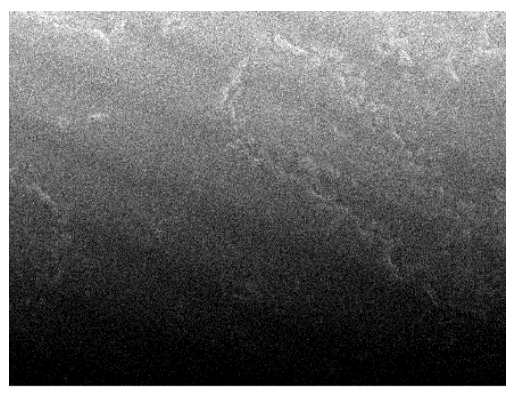

f)

Fig. 6. Microphotographs of the fracture surface of doped epoxy composites with different concentrations of dopant (wt \%): 5 (a), 10 (b), 20 (c), 30 (d), 40 (e) and 50 (f) 
Physical and nonlinear-optical parameters of polymer films

\begin{tabular}{|c|c|c|c|c|}
\hline Weight fraction of fisetin, $\mathrm{wt} \%$ & ${ }^{*} N$ & ${ }^{* *} F$ & ${ }^{* * *}<\cos ^{3} \theta>$ & $\chi^{(2)}, \mathrm{pm} / \mathrm{V}$ \\
\hline 5 & $2.05 \cdot 10^{21}$ & 15.24 & 0.548 & 6.01 \\
\hline 10 & $2.15 \cdot 10^{21}$ & 15.32 & 0.527 & 6.1 \\
\hline 20 & $2.41 \cdot 10^{21}$ & 15.50 & 0.465 & 6.11 \\
\hline 30 & $2.78 \cdot 10^{21}$ & 15.69 & 0.381 & 5.85 \\
\hline 40 & $3.36 \cdot 10^{21}$ & 15.91 & 0.313 & 5.8 \\
\hline 50 & $4.36 \cdot 10^{21}$ & 16.16 & 0.218 & 5.39 \\
\hline
\end{tabular}

Notes: *quantitative density of chromophore; ** local field correction factor; *** average alignment

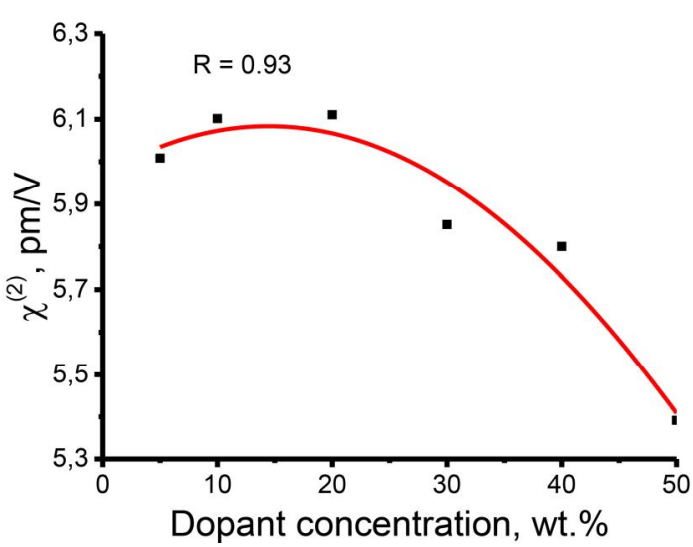

Fig. 7. Fisetin concentration effect on nonlinear properties of doped epoxy polymers

Fig. 7 shows the dependence of $\chi^{(2)}$ values on the chromophore concentration. The curve of this dependence has extreme character. The weight fraction of the dopant at which the macroscopic susceptibility is maximal equals to $20 \mathrm{wt} \%$. This is can be explained by the fact that at larger dopant concentrations the formed associates prevent dopant molecules orientation at the corona discharge electric field. These data are well correlated with previous thermal and morphological investigation.

An equally important parameter for using NLO polymer materials is their temporal stability after poling. The relaxation behavior of NLO films after poling was investigated by monitoring the decrease of $\Phi_{t} / \Phi_{0}$ ratio depending on the time at ambient temperature for 28 days. As shown in Fig. 8, after poling within 5 days the parameter $\Phi_{t} / \Phi_{0}$ decreases from 21 to $70 \%$ depending on the dopant concentration and then this parameter gradually decreases in time.

Such a phenomenon should be explained by the fact that the chromophore molecules are not covalently bound with the polymer matrix in doped polymer systems. It leads to the fact that the chromophore molecule due to thermal vibrations can freely rotate to a significant angle, leading to relaxation processes in time. Fig. 8 shows that there is no relationship between the dopant concentration and the decrease in NLO activity of polymer films in time.

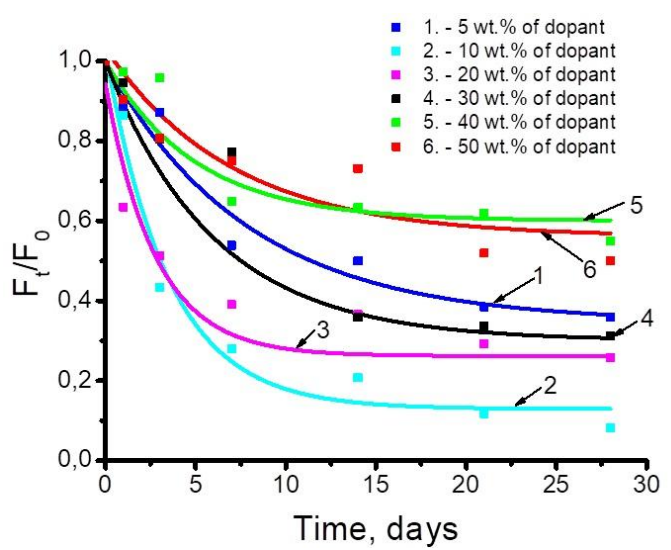

Fig. 8. Temporal stability of doped polymer films

In our opinion, this can be explained by the fact that the only obstacle to the free movement of chromophore molecules can be intermolecular hydrogen bond between hydroxyl groups of chromophore and chromophore molecules with polymer matrix, as well as the certain steric hindrances that may be related to microenvironment of chromophore molecules [20].

\section{Conclusions}

It was found that under polymer films synthesis conditions at least two forms of dopant molecules (neutral and anion) exist. Quantitative redistribution between these two forms with increasing concentration of dopant in the polymer matrix leads to different positions of the resulting maxima on the spectral curves. In addition, when the chromophore concentration is about $20 \mathrm{wt} \%$, its associates prevent dopant molecules orientation at the corona discharge electric field. These data correlate with performed morphological and thermal investigations. Relaxation of NLO properties shows a gradual decrease throughout the measurement period, due to the fact that in the doped polymer systems chromophore molecules are not covalently bound to the polymer matrix. Moreover, there is a concentration maximum that provides more or less acceptable values of macroscopic NLO susceptibility 
for the creation of NLO polymer materials based on epoxy polymers doped with $3,7,3^{\prime}, 4^{\prime}$ '- tetrahydroxyflavone.

\section{References}

[1] Lin W., Cui Y., Yu J. et al.: Dyes Pigments, 2017, 136, 791. https://doi.org/10.1016/j.dyepig.2016.09.040

[2] Wu J., Xiao H., Qiu L. et al.: RSC Adv., 2014, 91, 49737. https://doi.org/10.1039/c4ra09368b

[3] Mishurov D., Voronkin A., Roshal A. et al.: Opt. Mater., 2016, 57, 179. https://doi.org/10.1016/j.optmat.2016.03.047

[4] Mishurov D., Voronkin A., Roshal A.: Struct. Chem., 2015, 27, 285. https://doi.org/10.1007/s11224-015-0694-5

[5] Dalton L., Benight S.: Polymers, 2011, 3, 1325.

https://doi.org/10.3390/polym3031325

[6] Marder S., Kippelen B., Jen A., Peyghambarian N.: Nature, 1997, 6645, 845. https://doi.org/10.1038/42190

[7] Rengarajan T., Yaacob N.: Eur. J. Pharmacol., 2016, 789, 8. https://doi.org/10.1016/j.ejphar.2016.07.001

[8] Rajendran M., Ravichandran R., Devapiriam D.: Int. J. Comput. Appl., 2013, 77, 18. https://doi.org/10.5120/13382-1003

[9] Hanemann T., Böhm J., Honnef K. et al.: J. Macromol. Mater. Eng., 2007, 292, 285. https://doi.org/10.1002/mame.200600409

[10] Rau I., Armatys P., Chollet P. et al.: Chem. Phys. Lett., 2007, 442, 329. https://doi.org/10.1016/j.cplett.2007.05.058

[11] Doroshenko A.: Spectral Data Lab Software. Kharkiv 1999.

[12] Guo H., Liu L., Hao X. et al.: Opt. Laser Technol., 2011, 43,

1184. https://doi.org/10.1016/j.optlastec.2011.03.006

[13] Nakagawa I., Tsuchida A., Shimanouchi T.: J. Chem. Phys., 1967, 47, 982. https://doi.org/10.1063/1.1712066

[14] Davies G., Fedosov S., Carr P.: $9^{\text {th }}$ International Symposium on Electrets (ISE 9) Proceedings. China, Shanghai 1996, 437.

https://doi.org/10.1109/ise.1996.578124
[15] YilmazY., Kaya D., Pekcan Ö.: Eur. Phys. J. E., 2004, 15, 19. https://doi.org/10.1140/epje/i2003-10156-9

[16] Rotrekl J., Matejka L., Kapralkova L. et al.: eXPRESS Polym. Lett., 2012, 6, 975.

https://doi.org/10.3144/expresspolymlett.2012.103

[17] Xie H., Liu Z., Liu H. et al.: Polymer, 1998, 39, 2393. https://doi.org/10.1016/s0032-3861(97)00537-5

[18] Xie H., Huang X., Guo J.: Appl. Polym. Sci., 1996, 60, 537. https://doi.org/10.1002/(sici)1097-4628(19960425)60:4<537::aidapp7>3.0.co;2-p

[19] Shevchenko V., Sidorenko A., Bliznyuk V. et al.: Polym. Sci. A., 2013, 55, 1. https://doi.org/10.1134/s0965545x12100045

[20] Mishurov D., Voronkin A., Roshal A. et al.: Opt. Mater., 2017, 64, 166. http://dx.doi.org/10.1016/j.optmat.2016.12.004

Received: April 05, 2018 / Revised: May 05, 2018 / Accepted: September 14, 2018

\section{СИНТЕЗ ТА ХАРАКТЕРИСТИКА ДОПОВАНИХ ПОЛІМЕРНИХ ПЛІВОК ДЛЯ НЕЛІНІЙНОГО ОПТИЧНОГО ЗАСТОСУВАННЯ}

Анотація. Одержані і досліджені полімерні нелінійнооптичні (НЛО) матеріали на основі 3,7,3',4'-тетрагідроксифлавону $і$ ДГЕБА у вигляді тонких плівок. Визначено, щчо залежність значень макроскопічних нелінійно-оптичних сприйнятливостей $\left(\chi^{(2)}\right)$ допованих полімерних плівок від концентрації хромофору має екстремальний характер. Максимальне значення $\chi^{(2)}$ становить 6,11 nм/B за кониентрації допанту $20 \%$ мac.

Ключові слова: полімерні композити, доповані епоксидні полімери, хромофори, нелінійно оптичні властивості, фізетин. 